\title{
Initiation of human parturition: signaling from senescent fetal tissues via extracellular vesicle mediated paracrine mechanism
}

\author{
Ramkumar Menon \\ Division of Maternal-Fetal Medicine \& Perinatal Research, Department of Obstetrics \& Gynecology, The University of Texas Medical Branch at \\ Galveston, Galveston, TX, USA
}

\begin{abstract}
A better understanding of the underlying mechanisms by which signals from the fetus initiate human parturition is required. Our recent findings support the core hypothesis that oxidative stress (OS) and cellular senescence of the fetal membranes (amnion and chorion) trigger human parturition. Fetal membrane cell senescence at term is a natural physiological response to OS that occurs as a result of increased metabolic demands by the maturing fetus. Fetal membrane senescence is affected by the activation of the p38 mitogen activated kinase-mediated pathway. Similarly, various risk factors of preterm labor and premature rupture of the membranes also cause OS-induced senescence. Data suggest that fetal cell senescence causes inflammatory senescence-associated secretory phenotype (SASP) release. Besides SASP, high mobility group box 1 and cell-free fetal telomere fragments translocate from the nucleus to the cytosol in senescent cells, where they represent damage-associated molecular pattern markers (DAMPs). In fetal membranes, both SASPs and DAMPs augment fetal cell senescence and an associated 'sterile' inflammatory reaction. In senescent cells, DAMPs are encapsulated in extracellular vesicles, specifically exosomes, which are 30-150 $\mathrm{nm}$ particles, and propagated to distant sites. Exosomes traffic from the fetus to the maternal side and cause laborassociated inflammatory changes in maternal uterine tissues. Thus, fetal membrane senescence and the inflammation generated from this process functions as a paracrine signaling system during parturition. A better understanding of the premature activation of these signals can provide insights into the mechanisms by which fetal signals initiate preterm parturition.
\end{abstract}

Keywords: Amniochorion; Aging; Exosomes; Preterm birth; Fetal membranes

\section{Introduction}

Despite advances in medical care, the preterm birth (PTB) rate has been steady globally at up to $10.0 \%$ for the past several decades [1]. The most common phenotype (60\%) of PTB occurs spontaneously with $30-40 \%$ being preceded by preterm premature rupture of the fetal membranes (pPROM) [1]. Current interventions to reduce the risk of preterm labor have been designed primarily based on our understanding of signaling at the maternal myometrium, specifically in terms of minimizing contractions to prolong gestation. A higher rate of spontaneous PTB globally warrants a better understanding of these signals and their mechanisms that initiate normal term pregnancies, which can provide insights into the pathological activation of signals associated with preterm parturition [2].
PTB and pPROM are associated with intra-amniotic inflammation [3-8]. Sterile inflammation, in the absence of infection, is increasingly being reported in PTB and PPROM and

Received: 2019.01.02. Revised: 2019.03.06. Accepted: 2019.03.20. Corresponding author: Ramkumar Menon

Division of Maternal-Fetal Medicine \& Perinatal Research,

Department of Obstetrics and Gynecology, The University of Texas Medical Branch at Galveston, 11.138 Medical Research Building,

Galveston, TX 77555-0111, USA

E-mail: ram.menon@utmb.edu

https://orcid.org/0000-0001-9213-6105

Articles published in Obstet Gynecol Sci are open-access, distributed under the terms of the Creative Commons Attribution Non-Commercial License (http://creativecommons. org/licenses/by-nc/3.0/) which permits unrestricted non-commercial use, distribution, and reproduction in any medium, provided the original work is properly cited.

Copyright $\odot 2019$ Korean Society of Obstetrics and Gynecology 


\section{Obstetrics \& Gynecology Science}

Vol. 62, No. 4, 2019

is hypothesized to be a trigger for term birth as well $[9,10]$; however, etiologies contributing to sterile inflammation in adverse pregnancies are difficult to ascertain. This is partly because inflammatory pathways and biomarkers overlap, irrespective of the etiology [11]. Both infectious and noninfectious risk factors during pregnancy can cause oxidative stress (OS) and OS-mediated damage to cells and cellular organelles, which can lead to inflammation $[12,13]$. Similarly, in normal term pregnancies, OS-induced cellular damage and sterile inflammation can contribute to labor initiation pathways. Increased inflammation, irrespective of term or preterm status, is associated with decidual activation [14,15], transition of the quiescent myometrium to an active contractile state $[16,17]$, and cervical ripening $[2,18]$. However, the mechanisms that generate sterile inflammatory mediators that can affect normal term parturition have still not been elucidated.

Although signals initiating parturition may arise from both fetal and maternal uterine tissues; a precise understanding of the true initiator is yet to emerge. It is unclear on who (mother vs. fetus) determines the timing of the inflammatory activation on maternal uterine tissues. One of the theories is based on fetal organ maturation and endocrine signaling [19-23]. Mature fetal organs release various biochemical mediators into the uterine environment [24]. These biochemicals are pro-inflammatory and can increase the overall inflammatory load in feto-maternal uterine tissues to induce labor. A classic example was provided by Mendelson et al. [25], who reported the role of surfactant protein-A and platelet-activating factor (PAF) expression, which increased in the developing fetal lung. These proteins can increase myometrial inflammation and labor. Endocrine signals are also well-reported time determinants of parturition [26-30]. Tan et al. [17] and Mesiano et al. [31] described the functional progesterone withdrawal theory based on the changes in progesterone receptor function in the myometrium. The quiescent state of the myometrium is maintained during pregnancy via progesterone-progesterone receptor (PR) B function. At term, this state is compromised and the active labor state is generated when PRA phosphorylation and progesterone binding contribute to a pro-inflammatory milieu [17,32]. Similarly, cervical remodeling and ripening is also impacted by changes in the endocrine and inflammatory mediators in response to fetal maturation signals [18]. In summary, parturition is a timed event where the fetus signals mature through various biochemical and endocrine mediators. These biochemical mediators include, but are not limited to, platelet activation factor [33], endothelins [34-36], transforming growth factor [37], and platelet-derived growth factor, all of which enhance inflammation in various feto-maternal tissues. Thus, inflammation disrupts homeostasis of various uterine functions, resulting in labor-associated changes.

The functional impact on maternal uterine tissues imposed by various biochemical signals and the signal-generated pathways leading to inflammation, which transition a quiescent state to an active labor state, has been well-reported [38-43]. However, very few studies have examined the contributions of fetal tissues, specifically fetal membranes (amniochorion), in this process [44-56]. Fetal membranes line the intrauterine cavity where they are enriched by the amniotic fluid composed of various biochemicals produced by the maturing fetal organs. Disruption of the functional and mechanical integrity of the fetal membrane, chorioamnionitis (infiltration of leukocytes), or mechanical derangement in response to various endogenous and/or exogenous factors are antecedent to both term and preterm parturition [48,57-60]. Since fetal membranes act as a barrier between the fetus and uterine tissues, they play a major role in maintaining pregnancy by protecting the fetus. Fetal membranes are hypothesized to promote parturition as they are exposed to various biochemical and physiological stressors at term. These stressors can disrupt fetal membrane homeostasis, leading to their dysfunction and/or rupture. A stressed and inflamed fetal membrane can signal term parturition. Our laboratory has recently elucidated the mechanisms by which OS inducers contribute to parturition by forcing fetal membranes to undergo senescence, a mechanism of aging [61]. The aging of a cell is a non-reversible process and is often associated with sterile inflammation, referred to as the senescence-associated secretory phenotype (SASP) [62]. The rest of this review will be dedicated to summarizing the recent developments in fetal membrane senescence research and how membrane senescence may signal term and preterm parturition.

\section{Fetal membrane}

\section{Fetal membrane development}

Fetal membranes consist of 2 major cell layers: a single cuboidal amnion epithelial layer and the chorion trophoblast 


\section{Obstetrics \& Gynecology Science}

Ramkumar Menon. Senescent fetal cells signal parturition

layer. Both of these layers are connected to a collagen-rich extracellular matrix via type IV collagen-rich basement membranes. Amnion and chorion mesenchymal cells can be seen dispersed in this extracellular matrix. The development of the amnion and chorion begins with embryogenesis, although they do not participate directly in the formation of the embryo or fetus. Like the fetus, early growth of the amnion and chorion layers is rapid and independent of each other. The formation of the amniochorion as a combined structural unit is completed between the 13th and 15th week of gestation. The growth and development of the amniochorion correlate with fetal growth, with a longevity period of 40 weeks (term gestation period).

\section{Fetal membrane senescence}

Fetal membrane cells have stem cell-like properties, as they are capable of growth, DNA replication, and transition at term, as well as exhibiting stem cell transcription factors [63]. Recent work using primary amnion epithelial cells showed that these cells can proliferate, migrate, express stem cell markers, and transition into other cell types [63]. These properties are essential for fetal membrane remodeling and to maintain membrane integrity, as membranes during pregnancy are constantly subjected to shear stress and stretching because of the fluid and fetus, respectively. During growth, membrane cells are constantly shed and gaps referred to as microfractures are often created [64]. Stem cell-like properties, proliferation, and cell transitions help to rebuild any structural compromises created by cell shedding [63]. This process also generates localized inflammation, which is required for membrane matrix remodeling. Uterine cavity OS levels change during gestation [65-67]; however, redox balance during pregnancy sustains this remodeling process as well as other reproductive functions [68]. Interestingly, the process is stalled as the membrane reaches the end of its longevity period at term and demonstrates structural, functional, and biomolecular changes that are characteristic of aging [61]. Two key function-based definitions proposed by Masoro [69] and Finch [70] may aid in understanding the biological aging process of fetal membranes: 1) Fetal membranes are expected to deteriorate during gestation once its maturation is completed around the 12th week of pregnancy, and will be vulnerable to subtle changes in the intrauterine environment, decreasing survival ability; 2) Senescence is a mechanism associated with the deterioration process of the mem- branes, which alters its function and decreases vitality [71].

\section{Mechanism of fetal membrane senescence}

In normal pregnancies, the methodical progression of senescence is under physiological control and is an inevitable process [61]. Senescence in fetal membranes is a telomere-dependent process, where telomere (cap structures protecting chromosomal edges and biological markers of aging) lengths are progressively shortened as gestation progresses [71-73]. The "Hayflick Phenomenon" explains this process by demonstrating the halt in cell division after a certain number of divisions $[74,75]$. Telomere length reduction in fetal membranes inversely correlates with fetal growth and reduction peaks at term when the fetus is mature $[76,77]$. One of the key accelerators of telomere length reduction is OS, as the guaninerich telomere region is highly susceptible to OS $[78,79]$. As mentioned previously, redox balance maintains the structural remodeling of the membranes during gestation. However, term pregnancy is characterized by increased intrauterine OS due to the following reasons: 1 ) increase in the metabolic demands of the fetus $[80,81]$; 2) no change in the supplies of the maternal substrate to meet fetal metabolic demands $[82,83]$; 3) no change in the antioxidant status in both the fetal and maternal uterine tissues at term $[53,84]$; and 4 ) increase in the reactive oxygen species levels in the amniotic fluid at term when compared to other periods of gestation [85-88]. OS increase accelerates an already progressing aging process in fetal membranes through the activation of the p38 mitogen-activated protein kinase (p38MAPK) pathway, a stress-associated signaling pathway. OS specifically causes damage to various cell components, and this damage in fetal membranes can result in the activation of p38MAPK to cause senescence $[12,61,71,89-93]$. This mechanism of fetal membrane aging was confirmed when the antioxidant, $\mathrm{N}$-acetyl cysteine, and a p38MAPK inhibitor reversed OS-induced and p38MAPK-mediated senescence and the senescenceassociated secretory phenotype (SASP) in our in vitro and in situ animal models [13,90,92-94].

\section{Consequence of fetal membrane aging}

Fetal membranes attain an irreversible senescent phenotype due to increased OS prior to the initiation of labor at term. OS-p38MAPK-mediated senescence also diminishes the proliferative and transitional capacities of fetal membrane cells, thereby losing their functional and mechanical properties 


\section{Obstetrics \& Gynecology Science}

Vol. 62, No. 4, 2019

$[13,55,63,93,95]$. This deterioration in fetal membrane function at term is a natural and physiological indicator of fetal membrane longevity. As mentioned previously, the dysfunctional status of fetal membranes coincides with fetal organ maturation, thereby indicating fetal readiness for delivery. Senescence of the fetal membrane increases SASP, a unique inflammatory signature [61]. Therefore, senescence of fetal membranes can be detrimental to the existence of pregnancy as the inflammatory signals (SASP) from senescent fetal membranes are uterotonins and could potentially trigger parturition [61]. Besides SASP, senescence-associated cellular injury increases damage-associated molecular patterns (DAMPs; which consist of high mobility group box 1 [HMGB1], uric acid, S100 proteins [a family of 25 members], interleukin [IL]-33, heat-shock protein 70, and telomere fragments) in cell-free fetal DNA (cffDNA) from term membranes. DAMPs from senescent fetal membranes act as signals arising from the maturing fetus and generate inflammation in other intrauterine compartments, readying them for labor. We have also reported how DAMPs may exaggerate an ongoing inflammatory onslaught on fetal membrane and other tissues. A description of their functional contributions in terms of increasing overall inflammation is provided below.

HMGB1 exists predominantly as a nuclear $25 \mathrm{kDa}$, nonhistone chromatin-associated protein that binds doublestranded DNA and stabilizes nucleosomes during DNA repair and recombination $[96,97]$. However, the acetylation of lysine residues translocates HMGB1 to the cytoplasm, where it functions as a pro-inflammatory cytokine [98,99]. HMGB1 is known to be expressed in the human endometrium [100], placenta [101,102], decidua [101,103], cervix [104], fetal membrane cells $[105,106]$, and immune cells, and has been reported in chorioamnionitis cases $[105,107,108]$. Higher HMGB1 concentrations in the amniotic fluid of laboring (term and preterm) vs. non-laboring women suggest that it has a role in parturition [9]. An increase in HMGB1 indicates cellular damage, suggesting that it can be a critical mediator in both infectious and sterile inflammatory processes, as seen in both preterm and term labors. Buhimschi's lab showed the impact of HMGB1 in animal inflammation models and documented that RAGE-dependent HMGB1 induced the activation of fetal inflammation [109]. In our own studies using fetal membrane cells, we were able to demonstrate that HMGB1 secretion was higher in OS-induced fetal membrane cells [110]. HMGB1 utilizes a positive feedback loop to en- hance fetal cell senescence, tissue injury, and inflammatory cytokine production, which are capable of functioning as pro-parturition molecules. The enhancement of senescence by HMGB1 in these cells is mediated via Toll-like receptors (TLRs) and by increasing p38MAPK activation [110]. Interestingly, antioxidant, $\mathrm{N}$-acetyl cysteine, and p38MAPK inhibitor, SB203580, treatments reduced the pro-senescent and proinflammatory effect of HMGB1 on fetal membrane cells [110]. This mechanism is similar to the OS effect seen on fetal membranes, suggesting that HMGB1 released from an OSdamaged cell can enhance senescence and inflammation in a feed-forward loop [92].

Dr. Mark Phillippe's group $[111,112]$ has suggested that cffDNA in maternal circulation may activate human parturition. In his report, Dr. Phillippe [111]mentioned that an increase in cffDNA, which is released during apoptosis in the placenta and fetal membranes at term, has the ability to stimulate TLR9, leading to the increased release of cytokines and chemokines. One important component of cffDNA is fragmented telomeres. Telomere length in the fetal membranes decreases progressively throughout gestation with the shortest telomeres seen at term, which is consistent with in utero aging [72]. We also found a significant labor-associated increase in the abundance of cell-free fetal telomere fragments (cffTFs) in the amniotic fluid [73,113]. Additionally, cffTFs are also reported to have similar functional effects as HMGB1. To determine the functional consequences of increased cffTFs, in vitro and in situ animal model studies were conducted. Similar to the HMGB1 reports, cffTFs produced a positive feedback loop to enhance fetal cell senescence, tissue injury, and inflammatory cytokine production. Senescence induced by cffTFs were also associated with p38MAPK activation. To further determine the impact of cffTFs in parturition, we injected cffTFs into mouse models of pregnancy, thereby resulting in mouse fetal membrane p38MAPK activation, senescence, and inflammatory cytokine production $[94,113]$.

Although our studies were restricted to HMGB1 and cffTFs, other reports showed an association between other DAMPs like uric acid [102,114], S100 proteins [109,115], IL-33 [116], and HSP70 [117] during pregnancy complications [118]. In summary, parturition signaling can be viewed from the fetal membrane perspective, where a novel paracrine signaling mechanism mediated by fetal tissue stress (i.e., physiological or pathophysiological senescence and/or OS) generates 


\section{Obstetrics \& Gynecology Science}

Ramkumar Menon. Senescent fetal cells signal parturition

sterile inflammation within the maternal-fetal interface (fetal membranes, decidua, and myometrium). Term labor can be triggered by factors collectively referred to as DAMPs, which are produced from senescent fetal membrane cells.

\section{Can the mechanism of senescence explain the pathobiology of preterm birth and preterm premature rupture of the fetal membranes?}

The ultimate goal of all of these studies is to identify the initiators and mechanistic effectors of PTB and pPROM. Having determined that fetal membrane senescence may be one of the mechanisms triggering parturition at term, we examined similar pathways in PTB and pPROM. For this, fetal membranes and amniotic fluid samples were collected from women with PTB and pPROM. Molecular, biochemical, and histological markers were used to document differences in OS and antioxidant enzyme status, DNA damage, secondary signaling, MAPK activation, and senescence activation between the membranes in both groups. OS was higher and antioxidant enzymes were lower in PPROM when compared to PTB. PTB membranes had minimal OS and DNA damage, no p38MAPK activation, and minimal signs of senescence [119]. Conversely, pPROM had higher numbers of cells with OS, DNA damage, p38MAPK activation, and signs of senescence [119]. Telomere lengths were also substantially shorter in PPROM membranes than in PTB membranes and fetal cord blood samples supported the hypothesis that PPROM may have a pathology due to premature aging of membranes [72]. Histologically and biochemically, pPROM membranes resembled normal term-delivered membranes, whereas PTB membranes were distinctly different. Both PPROM and normal term birth are associated with fetal membrane senescence, inflammation, and dysfunction. Hence, pPROM is a disease of the fetal membrane where the premature activation of senescence predisposes them to rupture [120]. We concluded that PTB and PPROM arose from distinct pathophysiological pathways. OS and OS-induced cellular damage are likely determinants of signaling pathways and phenotypic outcomes. This conclusion does not rule out OS in PTB, as a subset of women with exposure to OS may still develop this pathway, ultimately leading to labor; however, it is more dominant in pPROM. We also postulate that pPROM is a disease of the fetal membrane and senescence, with senescence leading to dysfunctions that act as the primary mediators of this mechanism [120].

\section{How does fetal membrane senescence signal parturition?}

As detailed previously, in vitro and in situ animal models demonstrated the consequences of fetal membrane senescence. Senescence and sterile inflammation mediated by SASPs and DAMPs are uterotonins, which are capable of inducing labor. However, the question remains whether this inflammation and cellular damage is restricted to the membranes or if membrane-derived inflammatory mediators are propagated to other feto-maternal uterine tissues to trigger inflammatory changes. Although the diffusion of these mediators is possible, it is unlikely that molecules like HMGB1 can traverse through the feto-maternal tissue layers and still be functionally viable at distant sites [121]. Our group has hypothesized that signal propagation between feto-maternal tissues can be effectively achieved via extracellular vesicles, specifically exosomes, which are bioactive, spherical, cell-derived vesicles (30-150 nm in size) that are secreted during the process of exocytosis. Exosomes contain molecular constituents of their cell of origin, including proteins and RNA that reflect the physiological state of the cell source [122-125]. In addition to common membrane and cytosolic molecules, exosomes harbor unique cell-specific subsets of proteins. Exosomes are released from the cell when multi-vesicular bodies fuse with the plasma membrane. They contain high concentrations of cholesterol and detergent-resistant lipid membranes, which make them extremely stable and efficient carriers of molecules across tissue layers [126-128]. Exosomes mostly act as transporters of paracrine signals between tissues, but can regulate intracellular pathways by sequestering signaling molecules from the cytoplasm, thereby reducing their bioavailability $[127,128]$.

\section{Amniochorion cell-derived exosomes carry inflammatory mediators}

To test whether fetal membrane cells produced exosomes, we isolated and characterized primary amnion cell-derived 


\section{Obstetrics \& Gynecology Science}

Vol. 62, No. 4, 2019

exosomes. We also treated amnion cells with OS-inducing agents to mimic the conditions experienced at term. Amnion cells were previously shown to produce exosomes that exhibited classic characteristics; however, OS treatment changed their cargo contents [129]. Inflammation was also witnessed in exosomes derived from cells grown under normal conditions and in cells exposed to OS [129]. The nature of inflammatory mediators differed between normal and OStreated exosomes. Bioinformatic analysis of the proteomic contents in exosomes derived from cells grown under normal cell culture conditions exhibited nuclear factor (NF)-KB signaling pathways, whereas transforming growth factor $\beta$ (TGFB)-related signaling was dominant in OS-exposed cellderived exosomes. Although both represent inflammation, the underlying cellular physiology contributing to the distinct inflammatory mediators in the exosomes reflects the specific exposure and the OS-associated state of cells [129]. TGF $\beta$ has been previously reported to increase with term labor and is an activator of p38MAPK, a senescent inducer in fetal membranes [95]. Besides these inflammatory pathways, senescent amnion cell-derived exosomes (from amnion cells grown under OS conditions) contain HMGB1 and cffTFs. These exosomes also carry both genomic and mitochondrial DNA [130]. Although our published reports focus on amnion cell-derived exosomes, ongoing work in our laboratory demonstrates that amnion mesenchymal cells and chorion mesenchymal and trophoblast cells also generate exosomes with distinct cargo contents in response to various stimulants.

\section{Trafficking of exosomes carrying fetal signals between feto-maternal compartments}

Propagation of senescent fetal cell-derived signals via exosomes and the trafficking of exosomes from fetal to maternal compartments was previously determined using animal models [131]. In this study, pregnant CD-1 mice were intraamniotically injected on gestational days 16 and 17 with exosomes isolated from primary human amnion epithelial cells fluorescently labeled with the lipophilic dye, 1,1-dioctadecyl3,3,3,3-tetramethylindotricarbocyanine iodide (DiR). In vivo imaging of the mice showed fluorescence in the uterus on the exosome-injected side, whereas the uterine tissues on the non-injected side and in saline and dye alone-injected animals remained negative. Histological analysis of the placenta showed exosome migration from the fetal to the maternal side of the placenta. Fluorescence released from the exosomes was seen in maternal blood samples and in the maternal uterus and kidneys, demonstrating that exosomal cargo can be carried via the systemic route from the fetus to the maternal side of the uterine tissues during pregnancy. This supports our hypothesis that fetal signals can be delivered via exosomes to the maternal side. A similar form of exosomal trafficking was also reported by other study groups [132].

\section{Senescent fetal membrane-derived exosomes cause functional changes in maternal uterine cells}

After documenting fetal exosome traffic to the maternal side, we tested the hypothesis that fetal exosomes could produce inflammatory changes in maternal uterine cells. The pro-inflammatory effect of fetal exosomes on maternal cells will be considered as a signaling mechanism by the fetal membranes to initiate the labor process by enhancing the inflammatory load. To test this theory, primary amnion epithelial cells were grown in normal cell cultures or exposed to OS, and myometrial and decidual cells were treated with various doses of exosomes derived from amnion cells. Treatment resulted in the increased production of inflammatory mediators (IL-6, IL-8, and PGE2) and activation of NF-KB. This is suggestive of fetal membrane cell-derived exosomes contributing to labor-associated inflammatory changes in maternal uterine cells [133]. Similar to our data, Holder et al. [134] showed that macrophage-derived exosomes caused the release of pro-inflammatory cytokines from the placenta. Another study suggested the ability of the placenta to respond to maternal inflammatory signals mediated by the interaction of maternal immune cell exosomes [134].

Recently, we tested the hypothesis that exosomes, as paracrine signaling molecules, can cause parturition. For this, maternal plasma exosomes from CD-1 mice were isolated and characterized throughout gestation and the biological pathways associated with differentially-expressed cargo proteins were determined. The results indicated that the shape and size of the exosomes remained constant throughout the gestational period; however, a progressive increase in the 


\section{Obstetrics \& Gynecology Science}

Ramkumar Menon. Senescent fetal cells signal parturition

quantity of the exosomes carrying inflammatory mediators was observed from embryonic day 5 (E5) to E19. Moreover, intraperitoneal injection of E18 exosomes (enriched in inflammatory mediators) into E15 mice caused them to undergo PTB when compared to mice that were injected with E9 exosomes (minimal levels of inflammatory mediators) or normal saline. The injection of E18 exosomes produced inflammation in the cervix and uterus on the penultimate day of delivery. Thus, these results support the functional role of exosomes as paracrine signaling molecules in causing parturition. Notably, this study used total exosomes rather than fetal exosomes; therefore, it is not a true in situ replication of the reported in vitro data.

Studies have also reported about the role of exosomes in implantation [135,136], placental immunomodulation [137], and their biomarker potential in various pregnancy complications [135,138-143]. Abnormal quantity and cargo contents of exosomes may serve as biomarkers of various adverse pregnancy events. Thus, ongoing studies, both in our laboratory and many other laboratories, are examining the biomarker potential of exosomes in predicting PTB [134].

\section{Summary and conclusions}

PTB pathways, biomarkers, and intervention strategies remain an enigma in the obstetric world [144]. Although multiple initiator and effector signals from both the fetus and mother have been proposed, the rate of PTB continues to rise. Thus, this suggests that our current knowledge is inadequate to reduce PTB risk. A better understanding of normal term birth and its pathways is needed to re-examine the premature activation of such pathways as triggers during preterm labor conditions. This manuscript provides an overview of a novel mechanism of parturition initiation signal based on well-reported data. The data summarize the progressive senescence of fetal membrane cells as term approaches. Senescent fetal cells generate inflammatory cargo-laden exosomes that move from the fetus to maternal uterine tissues in order to cause parturition by promoting inflammation. This can be considered a signal from the fetus, or specifically the fetal membrane, which indicates its longevity and dysfunctional status. The loss of fetal membrane integrity due to senescence and generation of inflammation (SASPs and DAMPs) can be considered to be one of the signals required to initiate parturition. The premature activation of membrane senescence in response to various pregnancy-associated risk factors can be attributed to a major subset of PTBs and pPROM. A better understanding of senescence activators and exosomal signaling may help us to sub-classify PTBs with such pathologies. Exosomes may also serve as biomarkers indicative of risk status.

\section{Acknowledgements}

This work was supported by the National Institutes of Health/ National Institute of Child Health and Human Development (grant number 1R21Al140249-01A1 (NIH/NIAID) awarded to Menon R.

\section{Conflict of interest}

No potential conflict of interest relevant to this article was reported.

\section{References}

1. Beck S, Wojdyla D, Say L, Betran AP, Merialdi M, Requejo $\mathrm{JH}$, et al. The worldwide incidence of preterm birth: a systematic review of maternal mortality and morbidity. Bull World Health Organ 2010;88:31-8.

2. Romero R, Dey SK, Fisher SJ. Preterm labor: one syndrome, many causes. Science 2014;345:760-5.

3. Behnia F, Sheller S, Menon R. Mechanistic differences leading to infectious and sterile inflammation. Am J Reprod Immunol 2016;75:505-18.

4. Behnia F, Peltier MR, Saade GR, Menon R. Environmental pollutant polybrominated diphenyl ether, a flame retardant, induces primary amnion cell senescence. Am J Reprod Immunol 2015;74:398-406.

5. Sakata M, Sado T, Kitanaka T, Naruse K, Noguchi T, Yoshida $S$, et al. Iron-dependent oxidative stress as a pathogenesis for preterm birth. Obstet Gynecol Surv 2008;63:651-60.

6. Sussan TE, Sudini K, Talbot CC Jr, Wang X, Wills-Karp $M$, Burd I, et al. Nrf2 regulates gene-environment interactions in an animal model of intrauterine inflam- 


\section{Obstetrics \& Gynecology Science}

Vol. 62, No. 4, 2019

mation: implications for preterm birth and prematurity. Sci Rep 2017;7:40194.

7. Vadillo-Ortega F, Osornio-Vargas A, Buxton MA, Sánchez BN, Rojas-Bracho L, Viveros-Alcaráz M, et al. Air pollution, inflammation and preterm birth: a potential mechanistic link. Med Hypotheses 2014;82:219-24.

8. Cobo T, Kacerovsky M, Holst RM, Hougaard DM, Skogstrand K, Wennerholm UB, et al. Intra-amniotic inflammation predicts microbial invasion of the amniotic cavity but not spontaneous preterm delivery in preterm prelabor membrane rupture. Acta Obstet Gynecol Scand 2012;91:930-5.

9. Romero R, Miranda J, Chaiworapongsa T, Korzeniewski SJ, Chaemsaithong P, Gotsch F, et al. Prevalence and clinical significance of sterile intra-amniotic inflammation in patients with preterm labor and intact membranes. Am J Reprod Immunol 2014;72:458-74.

10. Horton JS, Yamamoto SY, Bryant-Greenwood GD. Relaxin modulates proinflammatory cytokine secretion from human decidual macrophages. Biol Reprod 2011;85:788-97.

11. Menon R, Fortunato SJ. Distinct pathophysiologic pathways induced by in vitro infection and cigarette smoke in normal human fetal membranes. Am J Obstet Gynecol 2009;200:334.e1-8.

12. Menon R. Oxidative stress damage as a detrimental factor in preterm birth pathology. Front Immunol 2014;5:567.

13. Polettini J, Richardson LS, Menon R. Oxidative stress induces senescence and sterile inflammation in murine amniotic cavity. Placenta 2018;63:26-31.

14. Gomez-Lopez N, StLouis D, Lehr MA, Sanchez-Rodriguez EN, Arenas-Hernandez M. Immune cells in term and preterm labor. Cell Mol Immunol 2014;11:571-81.

15. Erlebacher A. Immunology of the maternal-fetal interface. Annu Rev Immunol 2013;31:387-411.

16. Shynlova O, Tsui P, Jaffer S, Lye SJ. Integration of endocrine and mechanical signals in the regulation of myometrial functions during pregnancy and labour. Eur J Obstet Gynecol Reprod Biol 2009;144 Suppl 1:S2-10.

17. Tan H, Yi L, Rote NS, Hurd WW, Mesiano S. Progesterone receptor-A and -B have opposite effects on proinflammatory gene expression in human myometrial cells: implications for progesterone actions in human pregnancy and parturition. J Clin Endocrinol Metab
2012;97:E719-30.

18. Yellon SM. Contributions to the dynamics of cervix remodeling prior to term and preterm birth. Biol Reprod 2017:96:13-23.

19. Casey ML, MacDonald PC. The endocrinology of human parturition. Ann N Y Acad Sci 1997;828:273-84.

20. Casey ML, Winkel CA, Porter JC, MacDonald PC. Endocrine regulation of the initiation and maintenance of parturition. Clin Perinatol 1983;10:709-21.

21. Smith R, Nicholson RC. Corticotrophin releasing hormone and the timing of birth. Front Biosci 2007;12:912-8.

22. Smith R. Alterations in the hypothalamic pituitary adrenal axis during pregnancy and the placental clock that determines the length of parturition. J Reprod Immunol 1998;39:215-20.

23. McLean M, Bisits A, Davies J, Woods R, Lowry P, Smith R. A placental clock controlling the length of human pregnancy. Nat Med 1995;1:460-3.

24. Mendelson CR. Minireview: fetal-maternal hormonal signaling in pregnancy and labor. Mol Endocrinol 2009;23:947-54.

25. Mendelson CR, Montalbano AP, Gao L. Fetal-to-maternal signaling in the timing of birth. J Steroid Biochem Mol Biol 2017;170:19-27.

26. Pařízek A, Koucký M, Dušková M. Progesterone, inflammation and preterm labor. J Steroid Biochem Mol Biol 2014;139:159-65.

27. Goffinet F, Maillard F, Fulla Y, Cabrol D. Biochemical markers (without markers of infection) of the risk of preterm delivery. Implications for clinical practice. Eur J Obstet Gynecol Reprod Biol 2001;94:59-68.

28. Challis JR, Smith SK. Fetal endocrine signals and preterm labor. Biol Neonate 2001;79:163-7.

29. Petraglia F, Imperatore A, Challis JR. Neuroendocrine mechanisms in pregnancy and parturition. Endocr Rev 2010;31:783-816.

30. Keelan JA, Coleman M, Mitchell MD. The molecular mechanisms of term and preterm labor: recent progress and clinical implications. Clin Obstet Gynecol 1997:40:460-78.

31. Mesiano S, Welsh TN. Steroid hormone control of myometrial contractility and parturition. Semin Cell Dev Biol 2007;18:321-31.

32. Mesiano S, Chan EC, Fitter JT, Kwek K, Yeo G, Smith 


\section{Obstetrics \& Gynecology Science}

Ramkumar Menon. Senescent fetal cells signal parturition

R. Progesterone withdrawal and estrogen activation in human parturition are coordinated by progesterone receptor $A$ expression in the myometrium. J Clin Endocrinol Metab 2002;87:2924-30.

33. Sugano T, Narahara H, Nasu K, Arima K, Fujisawa K, Miyakawa I. Effects of platelet-activating factor on cytokine production by human uterine cervical fibroblasts. Mol Hum Reprod 2001;7:475-81.

34. Casey ML, Brown CE, Peters M, MacDonald PC. Endothelin levels in human amniotic fluid at mid-trimester and at term before and during spontaneous labor. J Clin Endocrinol Metab 1993;76:1647-50.

35. Schrey MP, Hare A. Endothelin-1 stimulates phospholipid hydrolysis and prostaglandin F2 alpha production in primary human decidua cell cultures. Prostaglandins Leukot Essent Fatty Acids 1992;47:321-5.

36. Usuki S, Saitoh T, Sawamura T, Suzuki N, Shigemitsu S, Yanagisawa $\mathrm{M}$, et al. Increased maternal plasma concentration of endothelin-1 during labor pain or on delivery and the existence of a large amount of endothelin-1 in amniotic fluid. Gynecol Endocrinol 1990;4:8597.

37. Romero R, Wu YK, Oyarzun E, Hobbins JC, Mitchell MD. A potential role for epidermal growth factor/alpha-transforming growth factor in human parturition. Eur J Obstet Gynecol Reprod Biol 1989;33:55-60.

38. Lindström TM, Bennett PR. The role of nuclear factor kappa B in human labour. Reproduction 2005;130:569-81.

39. Lappas M, Rice GE. The role and regulation of the nuclear factor kappa B signalling pathway in human labour. Placenta 2007;28:543-56.

40. Adams Waldorf KM, Singh N, Mohan AR, Young RC, Ngo L, Das A, et al. Uterine overdistention induces preterm labor mediated by inflammation: observations in pregnant women and nonhuman primates. Am J Obstet Gynecol 2015;213:830.e1-19.

41. Romero R, Gotsch F, Pineles B, Kusanovic JP. Inflammation in pregnancy: its roles in reproductive physiology, obstetrical complications, and fetal injury. Nutr Rev 2007;65:S194-202.

42. Lee Y, Sooranna SR, Terzidou V, Christian M, Brosens J, Huhtinen $\mathrm{K}$, et al. Interactions between inflammatory signals and the progesterone receptor in regulating gene expression in pregnant human uterine myocytes.
J Cell Mol Med 2012;16:2487-503.

43. Sivarajasingam SP, Imami N, Johnson MR. Myometrial cytokines and their role in the onset of labour. J Endocrinol 2016;231:R101-19.

44. Kumar D, Moore RM, Mercer BM, Mansour JM, Redline RW, Moore JJ. The physiology of fetal membrane weakening and rupture: insights gained from the determination of physical properties revisited. Placenta 2016;42:59-73.

45. Feng L, Ransom CE, Nazzal MK, Allen TK, Li YJ, Truong $T$, et al. The role of progesterone and a novel progesterone receptor, progesterone receptor membrane component 1 , in the inflammatory response of fetal membranes to Ureaplasma parvum infection. PLoS One 2016;11:e0168102.

46. Sato BL, Collier ES, Vermudez SA, Junker AD, KendalWright CE. Human amnion mesenchymal cells are proinflammatory when activated by the Toll-like receptor 2/6 ligand, macrophage-activating lipoprotein-2. Placenta 2016;44:69-79.

47. Kendal-Wright CE. Stretching, mechanotransduction, and proinflammatory cytokines in the fetal membranes. Reprod Sci 2007;14:35-41.

48. Gomez-Lopez N, Vadillo-Perez L, Hernandez-Carbajal A, Godines-Enriquez M, Olson DM, Vadillo-Ortega F. Specific inflammatory microenvironments in the zones of the fetal membranes at term delivery. Am J Obstet Gynecol 2011;205:235.e15-24.

49. Garfias Y, Zaga-Clavellina V, Vadillo-Ortega F, Osorio $M$, Jimenez-Martinez MC. Amniotic membrane is an immunosuppressor of peripheral blood mononuclear cells. Immunol Invest 2011;40:183-96.

50. Kim YM, Romero R, Chaiworapongsa T, Kim GJ, Kim MR, Kuivaniemi $H$, et al. Toll-like receptor-2 and -4 in the chorioamniotic membranes in spontaneous labor at term and in preterm parturition that are associated with chorioamnionitis. Am J Obstet Gynecol 2004;191:1346-55.

51. Hoang M, Potter JA, Gysler SM, Han CS, Guller S, Norwitz $E R$, et al. Human fetal membranes generate distinct cytokine profiles in response to bacterial Toll-like receptor and nod-like receptor agonists. Biol Reprod 2014;90:39.

52. Kim SH, MacIntyre DA, Firmino Da Silva M, Blanks AM, Lee YS, Thornton $S$, et al. Oxytocin activates NF- 


\section{Obstetrics \& Gynecology Science}

Vol. 62, No. 4, 2019

KB-mediated inflammatory pathways in human gestational tissues. Mol Cell Endocrinol 2015;403:64-77.

53. Lim R, Barker G, Lappas M. The transcription factor Nrf2 is decreased after spontaneous term labour in human fetal membranes where it exerts anti-inflammatory properties. Placenta 2015;36:7-17.

54. Lim R, Barker G, Lappas M. The TLR2 ligand FSL-1 and the TLR5 ligand Flagellin mediate pro-inflammatory and pro-labour response via MyD88/TRAF6/ NF-kB-dependent signalling. Am J Reprod Immunol 2014;71:401-17.

55. Menon R, Richardson LS, Lappas M. Fetal membrane architecture, aging and inflammation in pregnancy and parturition. Placenta 2019;79:40-5.

56. Li XQ, Zhu P, Myatt L, Sun K. Roles of glucocorticoids in human parturition: a controversial fact? Placenta 2014;35:291-6.

57. Murtha AP, Menon R. Regulation of fetal membrane inflammation: a critical step in reducing adverse pregnancy outcome. Am J Obstet Gynecol 2015;213:447-8.

58. Puthiyachirakkal M, Lemerand K, Kumar D, Moore $R$, Philipson $E$, Mercer BM, et al. Thrombin weakens the amnion extracellular matrix (ECM) directly rather than through protease activated receptors. Placenta 2013;34:924-31.

59. Castillo-Castrejon M, Meraz-Cruz N, Gomez-Lopez N, Flores-Pliego A, Beltrán-Montoya J, Viveros-Alcaráz $\mathrm{M}$, et al. Choriodecidual cells from term human pregnancies show distinctive functional properties related to the induction of labor. Am J Reprod Immunol 2014;71:86-93.

60. Menon R, Taylor RN, Fortunato SJ. Chorioamnionitis-a complex pathophysiologic syndrome. Placenta 2010;31:113-20.

61. Behnia F, Taylor BD, Woodson M, Kacerovsky M, Hawkins $\mathrm{H}$, Fortunato $\mathrm{SJ}$, et al. Chorioamniotic membrane senescence: a signal for parturition? Am J Obstet Gynecol 2015;213:359.e1-16.

62. Wei W, Ji S. Cellular senescence: molecular mechanisms and pathogenicity. J Cell Physiol 2018;233:912135.

63. Richardson L, Menon R. Proliferative, migratory, and transition properties reveal metastate of human amnion cells. Am J Pathol 2018;188:2004-15.

64. Richardson LS, Vargas G, Brown T, Ochoa L, Sheller-
Miller S, Saade GR, et al. Discovery and characterization of human amniochorionic membrane microfractures. Am J Pathol 2017;187:2821-30.

65. Burton GJ. Oxygen, the Janus gas; its effects on human placental development and function. J Anat 2009;215:27-35.

66. Jauniaux E, Poston L, Burton GJ. Placental-related diseases of pregnancy: involvement of oxidative stress and implications in human evolution. Hum Reprod Update 2006;12:747-55.

67. Myatt L. Review: reactive oxygen and nitrogen species and functional adaptation of the placenta. Placenta 2010;31 Suppl:S66-9.

68. Agarwal A, Gupta S, Sharma RK. Role of oxidative stress in female reproduction. Reprod Biol Endocrinol 2005;3:28.

69. Masoro EJ. Glucocorticoids and aging. Aging (Milano) 1995;7:407-13.

70. Finch CE. Mechanisms in senescence: some thoughts in April 1990. Exp Gerontol 1992;27:7-16.

71. Menon R. Human fetal membranes at term: dead tissue or signalers of parturition? Placenta 2016;44:1-5.

72. Menon R, Yu J, Basanta-Henry P, Brou L, Berga SL, Fortunato $S$, et al. Short fetal leukocyte telomere length and preterm prelabor rupture of the membranes. PLOS One 2012;7:e31136.

73. Menon R, Mesiano S, Taylor RN. Programmed fetal membrane senescence and exosome-mediated signaling: a mechanism associated with timing of human parturition. Front Endocrinol (Lausanne) 2017;8:196.

74. Hayflick L, Moorhead PS. The serial cultivation of human diploid cell strains. Exp Cell Res 1961;25:585-621.

75. Hayflick L. The establishment of a line (WISH) of human amnion cells in continuous cultivation. Exp Cell Res 1961;23:14-20.

76. Bonney EA, Krebs K, Saade G, Kechichian T, Trivedi J, Huaizhi $Y$, et al. Differential senescence in fetomaternal tissues during mouse pregnancy. Placenta 2016;43:26-34.

77. Menon R, Behnia F, Polettini J, Saade GR, Campisi J, Velarde M. Placental membrane aging and HMGB1 signaling associated with human parturition. Aging (Albany NY) 2016;8:216-30.

78. Kawanishi S, Oikawa S. Mechanism of telomere shortening by oxidative stress. Ann N Y Acad Sci 


\section{Obstetrics \& Gynecology Science}

Ramkumar Menon. Senescent fetal cells signal parturition

2004;1019:278-84

79. Wang Z, Rhee DB, Lu J, Bohr CT, Zhou F, Vallabhaneni $\mathrm{H}$, et al. Characterization of oxidative guanine damage and repair in mammalian telomeres. PLoS Genet 2010;6:e1000951.

80. Skarżyńska E, Żytyńska-Daniluk J, Lisowska-Myjak B. Correlations between ceruloplasmin, lactoferrin and myeloperoxidase in meconium. J Trace Elem Med Biol 2017:43:58-62.

81. Wilinska M, Borszewska-Kornacka MK, Niemiec T, Jakiel G. Oxidative stress and total antioxidant status in term newborns and their mothers. Ann Agric Environ Med 2015;22:736-40.

82. Rhoades RA, Ryder DA. Fetal lung metabolism. Response to maternal fasting. Biochim Biophys Acta 1981;663:621-9.

83. Girard JR, Ferré P, Gilbert M, Kervran A, Assan R, Marliss EB. Fetal metabolic response to maternal fasting in the rat. Am J Physiol 1977.232:E456-63.

84. Chai M, Barker G, Menon R, Lappas M. Increased oxidative stress in human fetal membranes overlying the cervix from term non-labouring and post labour deliveries. Placenta 2012;33:604-10.

85. Longini $M$, Perrone $S$, Vezzosi P, Marzocchi B, Kenanidis $A$, Centini $G$, et al. Association between oxidative stress in pregnancy and preterm premature rupture of membranes. Clin Biochem 2007;40:793-7.

86. Marinoni E, Di lorio R, Villaccio B, Alberini A, Rota F, Cosmi EV. Amniotic fluid nitric oxide metabolite levels and nitric oxide synthase localization in feto-placental tissues are modified in association with human labor. Eur J Obstet Gynecol Reprod Biol 2000;89:47-54.

87. Pressman EK, Thornburg LL, Glantz JC, Earhart A, Wall PD, Ashraf $M$, et al. Inflammatory cytokines and antioxidants in midtrimester amniotic fluid: correlation with pregnancy outcome. Am J Obstet Gynecol 2011;204:155.e1-7.

88. Menon R, Fortunato SJ, Milne GL, Brou L, Carnevale C, Sanchez SC, et al. Amniotic fluid eicosanoids in preterm and term births: effects of risk factors for spontaneous preterm labor. Obstet Gynecol 2011;118:12134.

89. Velarde MC, Menon R. Positive and negative effects of cellular senescence during female reproductive aging and pregnancy. J Endocrinol 2016;230:R59-76.
90. Menon R, Boldogh I, Hawkins HK, Woodson M, Polettini J, Syed TA, et al. Histological evidence of oxidative stress and premature senescence in preterm premature rupture of the human fetal membranes recapitulated in vitro. Am J Pathol 2014;184:1740-51.

91. Menon R, Polettini J, Syed TA, Saade GR, Boldogh I. Expression of 8-oxoguanine glycosylase in human fetal membranes. Am J Reprod Immunol 2014;72:75-84.

92. Menon R, Boldogh I, Urrabaz-Garza R, Polettini J, Syed TA, Saade GR, et al. Senescence of primary amniotic cells via oxidative DNA damage. PLoS One 2013;8:e83416.

93. Jin J, Richardson L, Sheller-Miller S, Zhong N, Menon R. Oxidative stress induces p38MAPK-dependent senescence in the feto-maternal interface cells. Placenta 2018;67:15-23.

94. Polettini J, Silva MG, Kacerovsky M, Syed TA, Saade $G$, Menon R. Expression profiles of fetal membrane nicotinamide adenine dinucleotide phosphate oxidases (NOX) 2 and 3 differentiates spontaneous preterm birth and pPROM pathophysiologies. Placenta 2014;35:188-94.

95. Richardson L, Dixon CL, Aguilera-Aguirre L, Menon R. Oxidative stress-induced TGF-beta/TAB1-mediated p38MAPK activation in human amnion epithelial cells. Biol Reprod 2018;99:1100-12.

96. Erlandsson Harris $H$, Andersson U. Mini-review: the nuclear protein HMGB1 as a proinflammatory mediator. Eur J Immunol 2004;34:1503-12.

97. Naglova H, Bucova M. HMGB1 and its physiological and pathological roles. Bratisl Lek Listy 2012;113:163-71.

98. Davalos AR, Kawahara M, Malhotra GK, Schaum N, Huang J, Ved U, et al. p53-dependent release of Alarmin HMGB1 is a central mediator of senescent phenotypes. J Cell Biol 2013;201:613-29.

99. Park JS, Gamboni-Robertson F, He Q, Svetkauskaite D, Kim JY, Strassheim D, et al. High mobility group box 1 protein interacts with multiple Toll-like receptors. Am J Physiol Cell Physiol 2006;290:C917-24.

100. Zicari A, Centonze C, Realacci M, Buchetti B, Pietropolli $A$, Ticconi $C$. Estradiol 17- $\beta$ and progesterone modulate inducible nitric oxide synthase and high mobility group box 1 expression in human endometrium. Reprod Sci 2008;15:559-66.

101. Holmlund U, Wähämaa H, Bachmayer N, Bremme K, 


\title{
Obstetrics \& Gynecology Science
}

\author{
Vol. 62, No. 4, 2019
}

Sverremark-Ekström E, Palmblad K. The novel inflammatory cytokine high mobility group box protein 1 (HMGB1) is expressed by human term placenta. Immunology 2007;122:430-7.

102. Girard S, Heazell AE, Derricott H, Allan SM, Sibley CP, Abrahams VM, et al. Circulating cytokines and alarmins associated with placental inflammation in high-risk pregnancies. Am J Reprod Immunol 2014;72:422-34.

103. Stephen $\mathrm{GL}$, Lui $\mathrm{S}$, Hamilton $\mathrm{SA}$, Tower $\mathrm{CL}$, Harris LK, Stevens $A$, et al. Transcriptomic profiling of human choriodecidua during term labor: inflammation as a key driver of labor. Am J Reprod Immunol 2015;73:3655.

104. Dubicke A, Andersson P, Fransson E, Andersson E, Sioutas $A$, Malmström $A$, et al. High-mobility group box protein 1 and its signalling receptors in human preterm and term cervix. J Reprod Immunol 2010;84:86-94.

105. Baumbusch MA, Buhimschi CS, Oliver EA, Zhao G, Thung S, Rood K, et al. High mobility group-box 1 (HMGB1) levels are increased in amniotic fluid of women with intra-amniotic inflammation-determined preterm birth, and the source may be the damaged fetal membranes. Cytokine 2016;81:82-7.

106. Romero R, Chaiworapongsa T, Alpay Savasan Z, Xu $Y$, Hussein $Y$, Dong $Z$, et al. Damage-associated molecular patterns (DAMPs) in preterm labor with intact membranes and preterm PROM: a study of the alarmin HMGB1. J Matern Fetal Neonatal Med 2011;24:144455.

107. Romero R, Chaiworapongsa T, Savasan ZA, Hussein $Y$, Dong Z, Kusanovic JP, et al. Clinical chorioamnionitis is characterized by changes in the expression of the alarmin HMGB1 and one of its receptors, SRAGE. J Matern Fetal Neonatal Med 2012;25:558-67.

108. Plazyo O, Romero R, Unkel R, Balancio A, Mial TN, Xu Y, et al. HMGB1 induces an inflammatory response in the chorioamniotic membranes that is partially mediated by the inflammasome. Biol Reprod 2016;95:130.

109. Buhimschi CS, Baumbusch MA, Dulay AT, Oliver $E A$, Lee $S$, Zhao $G$, et al. Characterization of RAGE, HMGB1, and S100beta in inflammation-induced preterm birth and fetal tissue injury. Am J Pathol 2009;175:958-75.

110. Bredeson S, Papaconstantinou J, Deford JH, Kechich- ian T, Syed TA, Saade GR, et al. HMGB1 promotes a p38MAPK associated non-infectious inflammatory response pathway in human fetal membranes. PLoS One 2014;9:e113799.

111. Phillippe M. Cell-free fetal DNA, telomeres, and the spontaneous onset of parturition. Reprod Sci 2015;22:1186-201.

112. Phillippe M. Cell-free fetal DNA--a trigger for parturition. N Engl J Med 2014;370:2534-6.

113. Polettini J, Behnia F, Taylor BD, Saade GR, Taylor RN, Menon R. Telomere fragment induced amnion cell senescence: a contributor to parturition? PLoS One 2015;10:e0137188.

114. Mulla MJ, Myrtolli K, Potter J, Boeras C, Kavathas PB, Sfakianaki AK, et al. Uric acid induces trophoblast IL$1 \beta$ production via the inflammasome: implications for the pathogenesis of preeclampsia. Am J Reprod Immunol 2011;65:542-8.

115. Brien ME, Baker B, Duval C, Gaudreault V, Jones RL, Girard S. Alarmins at the maternal-fetal interface: involvement of inflammation in placental dysfunction and pregnancy complications. Can J Physiol Pharmacol 2019;97:206-12.

116. Huang B, Faucette AN, Pawlitz MD, Pei B, Goyert JW, Zhou JZ, et al. Interleukin-33-induced expression of PIBF1 by decidual $B$ cells protects against preterm labor. Nat Med 2017;23:128-35.

117. Chaiworapongsa T, Erez O, Kusanovic JP, Vaisbuch E, Mazaki-Tovi S, Gotsch F, et al. Amniotic fluid heat shock protein 70 concentration in histologic chorioamnionitis, term and preterm parturition. J Matern Fetal Neonatal Med 2008;21:449-61.

118. Nadeau-Vallée M, Obari D, Palacios J, Brien MĖ, Duval $C$, Chemtob $S$, et al. Sterile inflammation and pregnancy complications: a review. Reproduction 2016;152:R277-92.

119. Dutta EH, Behnia F, Boldogh I, Saade GR, Taylor BD, Kacerovský $M$, et al. Oxidative stress damage-associated molecular signaling pathways differentiate spontaneous preterm birth and preterm premature rupture of the membranes. Mol Hum Reprod 2016;22:143-57.

120. Menon R, Richardson LS. Preterm prelabor rupture of the membranes: a disease of the fetal membranes. Semin Perinatol 2017:41:409-19.

121. Zandarashvili L, Sahu D, Lee K, Lee YS, Singh P, Raja- 


\section{Obstetrics \& Gynecology Science}

Ramkumar Menon. Senescent fetal cells signal parturition

rathnam K, et al. Real-time kinetics of high-mobility group box 1 (HMGB1) oxidation in extracellular fluids studied by in situ protein NMR spectroscopy. J Biol Chem 2013;288:11621-7.

122. Salomon C, Nuzhat Z, Dixon CL, Menon R. Placental exosomes during gestation: liquid biopsies carrying signals for the regulation of human parturition. Curr Pharm Des 2018;24:974-82.

123. Jin J, Menon R. Placental exosomes: a proxy to understand pregnancy complications. Am J Reprod Immunol 2018;79:e12788.

124. Mincheva-Nilsson L, Baranov V. Placenta-derived exosomes and syncytiotrophoblast microparticles and their role in human reproduction: immune modulation for pregnancy success. Am J Reprod Immunol 2014;72:440-57.

125. Redman CW, Sargent IL. Circulating microparticles in normal pregnancy and pre-eclampsia. Placenta 2008;29 Suppl A:S73-7.

126. van Niel G, Porto-Carreiro I, Simoes S, Raposo G. Exosomes: a common pathway for a specialized function. J Biochem 2006;140:13-21.

127. Frydrychowicz M, Kolecka-Bednarczyk A, Madejczyk M, Yasar S, Dworacki G. Exosomes - structure, biogenesis and biological role in non-small-cell lung cancer. Scand J Immunol 2015;81:2-10.

128. György B, Szabó TG, Pásztói M, Pál Z, Misják P, Aradi $B$, et al. Membrane vesicles, current state-of-the-art: emerging role of extracellular vesicles. Cell Mol Life Sci 2011;68:2667-88.

129. Sheller S, Papaconstantinou J, Urrabaz-Garza R, Richardson L, Saade G, Salomon C, et al. Amnionepithelial-cell-derived exosomes demonstrate physiologic state of cell under oxidative stress. PLoS One 2016;11:e0157614.

130. Sheller-Miller S, Urrabaz-Garza R, Saade G, Menon R. Damage-associated molecular pattern markers HMGB1 and cell-Free fetal telomere fragments in oxidativeStressed amnion epithelial cell-derived exosomes. J Reprod Immunol 2017;123:3-11.

131. Sheller-Miller S, Lei J, Saade G, Salomon C, Burd I, Menon R. Feto-maternal trafficking of exosomes in murine pregnancy models. Front Pharmacol 2016;7:432.

132. Chang G, Mouillet JF, Mishima T, Chu T, Sadovsky E, Coyne $C B$, et al. Expression and trafficking of placen- tal microRNAs at the feto-maternal interface. FASEB J 2017;31:2760-70.

133. Hadley EE, Sheller-Miller S, Saade G, Salomon C, Mesiano S, Taylor RN, et al. Amnion epithelial cell-derived exosomes induce inflammatory changes in uterine cells. Am J Obstet Gynecol 2018;219:478.e1-21.

134. Holder B, Jones T, Sancho Shimizu V, Rice TF, Donaldson $B$, Bouqueau $M$, et al. Macrophage exosomes induce placental inflammatory cytokines: a novel mode of maternal-placental messaging. Traffic 2016;17:168-78.

135. Burnett LA, Nowak RA. Exosomes mediate embryo and maternal interactions at implantation and during pregnancy. Front Biosci (Schol Ed) 2016;8:79-96.

136. Kurian NK, Modi D. Extracellular vesicle mediated embryo-endometrial cross talk during implantation and in pregnancy. J Assist Reprod Genet 2019;36:189-98.

137. Jasti S, Farahbakhsh M, Nguyen S, Petroff BK, Petroff MG. Immune response to a model shared placenta/ tumor-associated antigen reduces cancer risk in parous mice. Biol Reprod 2017;96:134-44.

138. Morgan TK. Cell- and size-specific analysis of placental extracellular vesicles in maternal plasma and preeclampsia. Transl Res 2018;201:40-8.

139. Salomon C, Guanzon D, Scholz-Romero K, Longo S, Correa P, Illanes SE, et al. Placental exosomes as early biomarker of preeclampsia: potential role of exosomal microRNAs across gestation. J Clin Endocrinol Metab 2017;102:3182-94.

140. Sargent I. Microvesicles and pre-eclampsia. Pregnancy Hypertens 2013;3:58.

141. Pohler KG, Green JA, Moley LA, Gunewardena S, Hung WT, Payton RR, et al. Circulating microRNA as candidates for early embryonic viability in cattle. Mol Reprod Dev 2017;84:731-43.

142. Pillay P, Moodley K, Moodley J, Mackraj I. Placenta-derived exosomes: potential biomarkers of preeclampsia. Int J Nanomedicine 2017;12:8009-23.

143. Menon R, Debnath C, Lai A, Guanzon D, Bhatnagar $S$, Kshetrapal PK, et al. Circulating exosomal miRNA profile during term and preterm birth pregnancies: a longitudinal study. Endocrinology 2019;160:249-75.

144. Menon R. Spontaneous preterm birth, a clinical dilemma: etiologic, pathophysiologic and genetic heterogeneities and racial disparity. Acta Obstet Gynecol Scand 2008;87:590-600. 